\title{
Design the Optimum Sizes and Analysis Shapes of Gantry Machines
}

\author{
V. Balaji, R. Selvam
}

\begin{abstract}
In the present day's need of the special purpose machine is more to the industries. Earlier heavy load carrying machines are there that to in open place only. By taking them in consideration in this paper made such that must lift 1 ton capacity weight with very effective in operation and maintenance in small area of industry. The initial period many type of gantry are used to lift the heavy load and problem with that is they were heavy in structure and completely manually one. So designing the new structure with new technology which can easily pick the material and place to another place using gantry in small scale industry. Redesigning the structure reducing the material to save the cost of structure. In this project gantry design is developed by considering present development in machinery, it helps to pick and place the heavy parts in rail transportation, aerospace and other automobile industries. In this paper going to discuss how the beam will deform when it having self-weight, gravity loading, structural analysis and modal analysis is done on the machine which shows the results like stresses and displacement, to reduce the cost of the machine, thickness of machine columns is reduced and this is the type of optimization carried out here. The amount of strength and stiffness is maintained same as the original model and all results compared to the original model, the structural analysis and modal which is of main result viewing in the whole work.
\end{abstract}

Key Words: Loading Condition, Structural Analysis, Optimization of Structural Analysis, Model Analysis.

\section{INTRODUCTION}

The initial period many type of gantry are used to lift the heavy load and problem with that is they were heavy in structure and completely manually one. So designing the new structure with new technology which can easily pick the material and place to another place using gantry in small scale industry. Redesigning the structure reducing the material to save the cost of structure.

The developed in 1959, which has the capacity to lift the load of 840 tones to a minimum height of 60 meters, the gantry which is of 140 metre height. After a long gap in 2008 the world's strongest gantry builted which can lift 20,000 metric tons that is in Yantai china, in 2012 planned to build 22,000 ton capacity of gantry in Qidong city, china That time industry are using to lift small and heavy items near a

Revised Manuscript Received on December 30, 2019.

* Correspondence Author

Dr. V. Balaji*, Department of Mechanical Engineering, Sri Sai Institute of Technology and Science, Rayachoty, Andhra Pradesh, India. E-mail: vbalaji_b1980@yahoo.co.in

Dr. R. Selvam, Department of Mechanical Engineering, Saveetha Engineering College, Chennai, India. E-mail:selvam_r7@ yahoo.com.

(C) The Authors. Published by Blue Eyes Intelligence Engineering and Sciences Publication (BEIESP). This is an open access article under the CC BY-NC-ND license (http://creativecommons.org/licenses/by-nc-nd/4.0/) working area of machine shop and automobile engine. Gantry machine the beam is an important part and its deformation, which has both machine accuracy and machine enactment, here discussed FEM of gantry machine. [4].

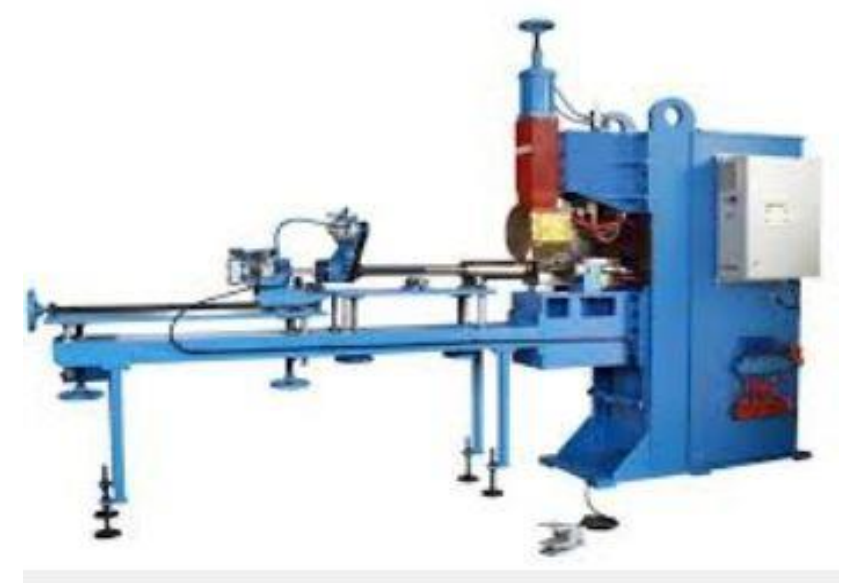

Fig: 1 Gantry Machine Image

The first resonance frequency and work space using the optimization based on functional dependency and geometry. gantry machine which having large work space for accessible by compared to many machines, so using optimization got kinematic design and gives the work space and frequency more than 50hz [5]. In this paper studied on structural analysis of gantry CNC machine how much strength that gantry beam can withstand and got the deformation as well as stress distribution of beam. Under the each condition the result varied and got deformation of $6.69 * 10^{-5} \mathrm{~m}$ the maximum stress is $1.18 * 10^{7} \mathrm{~Pa}$. The design of that cross beam well to do that work. For further analysis of optimization and structural analysis all for the good improvement of beam of the gantry machine. In this paper concluded that load which having on the gantry of beam so structural analysis is must need to know after that can see further optimization part later [6]. Some paper discussed the finite element and modal analysis theory had carried out here for better improvement of performance as well as structure of machine with static and dynamic analysis and predicting optimal design for optimization. The model selected for 3d CAD and Modeling software like UG NX 4.0 and ANSYS used to set the beam and the performance of optimization with static and dynamic characteristics parameter are more super double structure of wall, the topology optimization method which determine the optimal structure[7]. Gantry beam it is part of full machine to which static analysis given on the stress position using FE analysis, without changing geometry size optimized to it so gantry beam stiffness and strength increased, 
To improve reliability of that beam strengthening ribs added to it gantry beam quality reduced and optimized the gantry.

Beam which is large and heavy design problem of gantry so analysed that part by primarily if the no ribs used to improve the structural design of beam rib of machine[8]. Large gantry machine which is of huge volume the designer wants to re do the design which exist now, which having the same structure and component so he has to think that existing design having properties should change to new or not. So Zhang extracted the structure of that machine and improved in new design. Yan conducted new research on machine component with FEA to produce an optimization generalised model, at last they concluded that large component of design is reduced compared to actual design with the cost [9]. Some paper showed that optimization analysis of beam for that in this paper showed how the first ribs plate from cross beam obtained by optimization and feasibility result got by simulation the purpose of knowing natural frequency is function and static performance and static and dynamic character is analysed, at last got the natural frequencies of the cross beam of optimal are more by $19 \%$. In this paper concluded that to improve the stiffness of the cross beam and lighten the weight of machine as well as the anti-vibration performance so this is to show that how optimization works to reduce cost of structure [10]. In this paper showed that beam of gantry which tells about weight and apron of beam of that which relatively see the deformation of amplitude gantry machine characteristics and design of processing and structural one to improve size of assembly using FEA of deformation compared to real measured value. Concluded that before any problem caused by the beam deformation that solved and improvement in the beam distortion improved precision life of that beam [11].

Some paper showed improves dynamic performance in product static correct method in design, analysis and modal frequencies as well as improvement in model after these many test carried out by them Abacus FE software and impact test module based on gantry frame modal based. Simulation with combination of structural dynamic characteristic's and structure design are huge cost. So simulation play wide range role in long life more used in industries. They showed about structure but not thought about cost because they presented that life of machine best and better in the area [12].The gantry machine main plays a role in engineering application like aerospace, rail transportation and other industry to move items from one place to other, the beam of gantry machine which plays important role in dynamic and static characteristics. IBaoji used the finite element software and come to know that deformation of beam from that structure. Hou Hong ling determined the modal characteristics and showed first order frequencies, compared with the structural deformation [2].To reduce the cost of machine optimization requires mainly includes shape optimization, size optimization and topological optimization. Structural optimization is high level in topological optimization; topology information is carried out here. Wang' in Dalian university he carried out the topological optimization on a cross beam in gantry machine and finally 6\% lighter than original, then Jun Xin Liu and Zhi Dong Li used guide-weight method to solve topological optimization by having multiple loads. Traditional design replaced by structure optimization with goal oriented systematic method, the main thing is to see the lowest cost with best performance of structure using topology optimization it's also known as structural layout [5]. They explained that gantry machines rigidity can reduced due to the operation of heavy loads and vibration depend on dynamic behaviour full operation period. For that purpose they reduced the weights of loads and if not re design that model which by using the property based on the original one if the strength is more by changing design than its good to use the structure for industrial use [6].

\section{METHODS /EXPERIMENTAL}

\section{A.Aim of the study}

The earlier industries existing design are quite versatile, here designed model based on existing models only but differs in materials properties and strength of the structure varies, in this project expected to have a good capability of lifting the weights with accuracy and mobility must maintained. The earlier design structures are huge with that expenses of manufacturing also too high, so in this re designed model which is optimized to save the cost and expected effective work operation within required time

- A well designed material handling machine with a good operator.

- The machine should have well capability of lifting the weights.

- The task should be complete within the time.

- The accuracy and mobility should be maintained.

- Industry needs less expensive in purchasing machines with effective work operation.

- Special purpose machines are most likely used in industries now a days.

\section{EXPERIMENTAL WORK}

\section{A.Design and Development}

The study which consider that the design and analysis with development of the gantry machine, the CAD model to which carried out the analysis using the FE software the main aim to conclude is designed model must withstand the weight, comparing to earlier gantry which are used to lift heavy loads, the company Nova global techno soft private limited, the project which is carried out there, the designed model having capacity of lifting ton of loads with that reduced the cost the machine by optimization, it is specially for cost effective and must retained its strength and stiffness. 
CAD MODEL

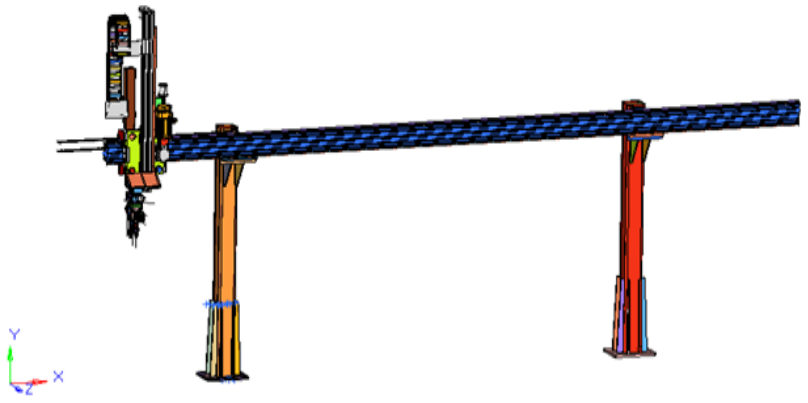

Fig 2. CAD Model of Gantry Machine

IV. SETTING OF THE STUDY

Gravity Loading Applied for different position and check for the deformation of Solid Beam for different position

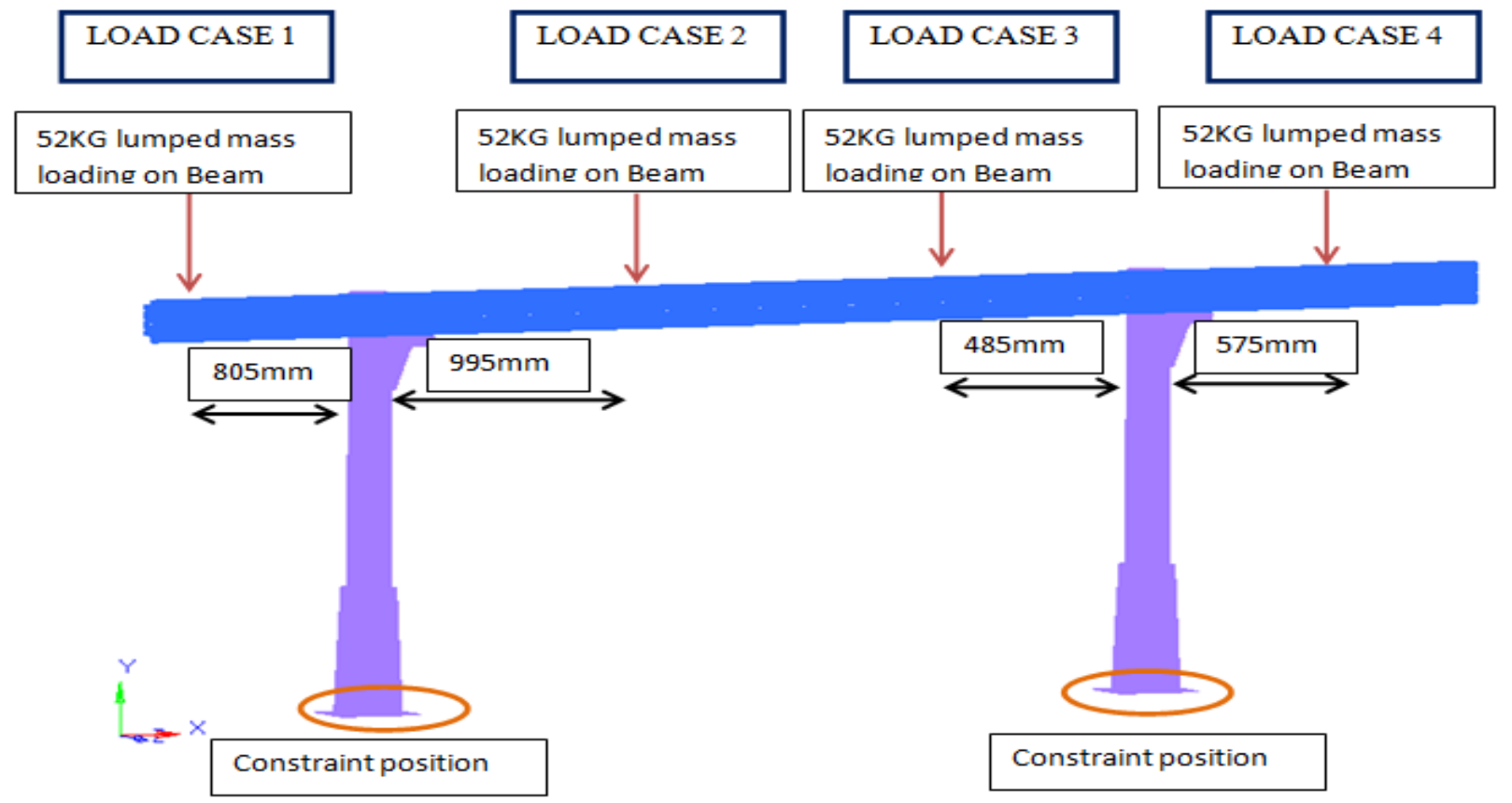

Fig 3 Loading Condition of Gantry Machine

\section{MATERIAL PROPERTIES}

\section{A. Steel Aluminum}

\begin{tabular}{|l|l|}
\hline $\begin{array}{l}\text { Elastic Modulus - } \\
2.1 \mathrm{e} 5 \mathrm{~N} / \mathrm{mm}^{2}\end{array}$ & $\begin{array}{l}\text { Elastic Modulus - } \\
0.70 \mathrm{e} 5 \mathrm{~N} / \mathrm{mm}^{2}\end{array}$ \\
\hline $\begin{array}{l}\text { Poisson's Ratio - 0.3 } \\
\begin{array}{l}\text { Steel Density - 7.8e-9 } \\
\text { Ton/mm }\end{array}\end{array}$ & Poisson's Ratio - 0.35 \\
\hline Yield Stress - 240Mpa $2.70 \mathrm{e}-9$ Tonne $/ \mathrm{mm}^{3}$ \\
\hline
\end{tabular}

Using hyper mesh analysis is carried out here, considering a beam of gantry machine four loads are acting on it, for each load structural analysis took as well as modal analysis, after getting the result stress which are compared to four loads and Optimization did for the model to reduce cost of machine.

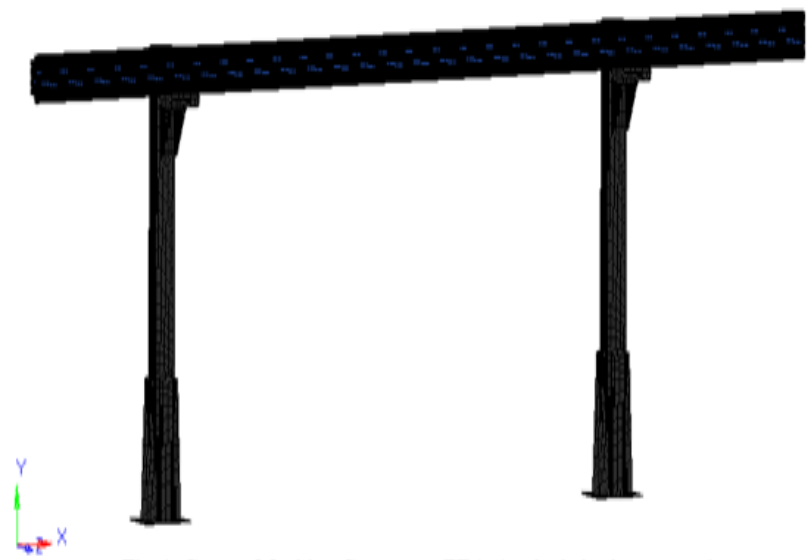

Fig 4. Gantry Machine Structure- EEA Analysis by hyper mesh 


\section{RESULTS AND DISCUSSIONS}

\section{A.Structural Analysis (without optimization)}

Structural analysis which determine the effect of loads on structure as well as their components. The structure mainly subjected to the analysis must withstand loads for Example Bridge, vehicle, furniture, biological tissue. Structural analysis used to show the fitness of thing tested. Which saves the physical test it is the most important part in engineering to know design of structure, it mainly incorporate field of applied maths, material science to compute deformation of structure, forces of internal and stress, reaction which support to it stability. In structural analysis mainly see the Structure and Load .Structure which refers as body used to support the load in civil we use to observe, in other branches ship and aircraft frames, pressure vessel, mechanical system. It is for safety purpose to do this test and an engineer must see the serviceability and safety.

Note: Total force applied in negative $Y$ direction for all 4 conditions.

Load Case: 1 (805mm left end)

1. Total Maximum Displacement: $0.817 \mathrm{~mm}$

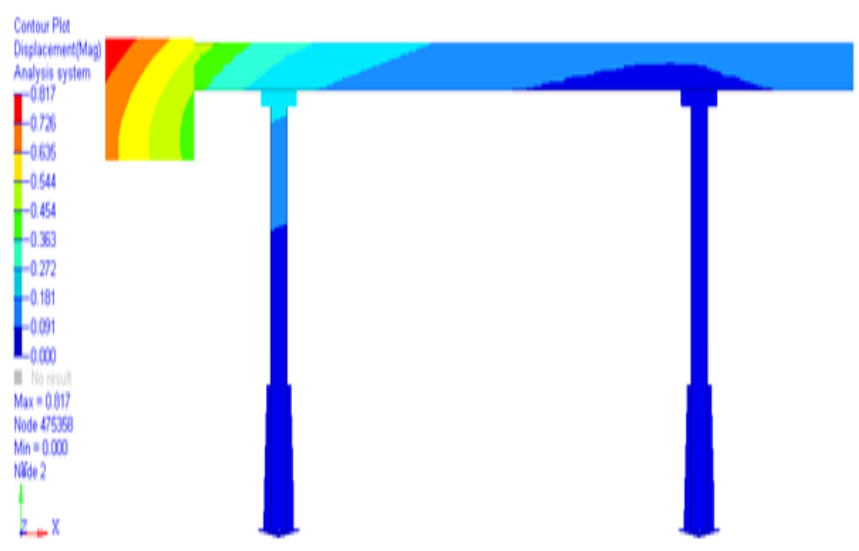

Fig. 5 Maximum displacementfor case-1

\section{A Total Maximum Stress: 6.925 Mpa}

(Safer limit Compared to Yield stress 240Mpa)

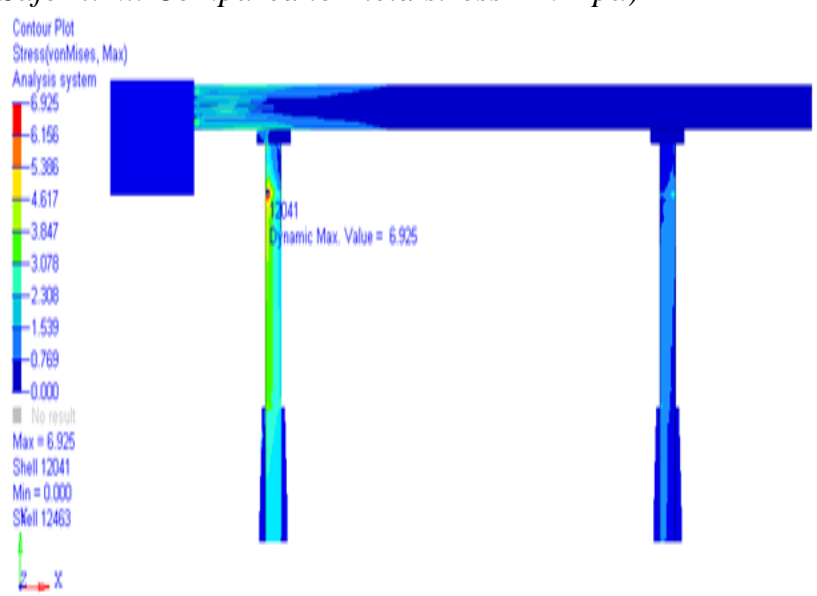

Fig 6 6laximum Stress for case-1

\section{B Maximum Stress At Beam Section}

This section we got minimum stress Such as $0.011 \mathrm{Mpa}$, $0.003 \mathrm{Mpa}$ and 0.015 Mpa.

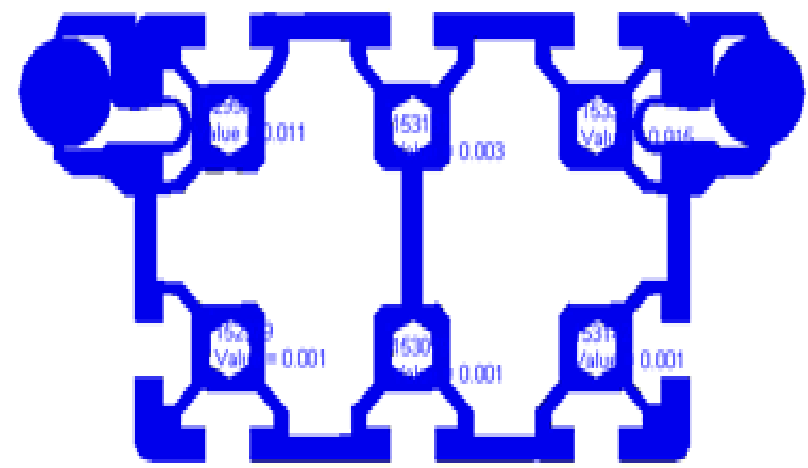

Fig 7 Maximum Stress at beam section for case-1

\section{A Maximum Shear Stress Areas: 3.962mpa.}


Fig 8. Maximum Shear Stress for case-l

\section{B Maximum Shear Stress At Beam Section}

This section we got minimum stress Such as $0.006 \mathrm{Mpa}$, $0.002 \mathrm{Mpa}$ and $0.001 \mathrm{Mpa}$.

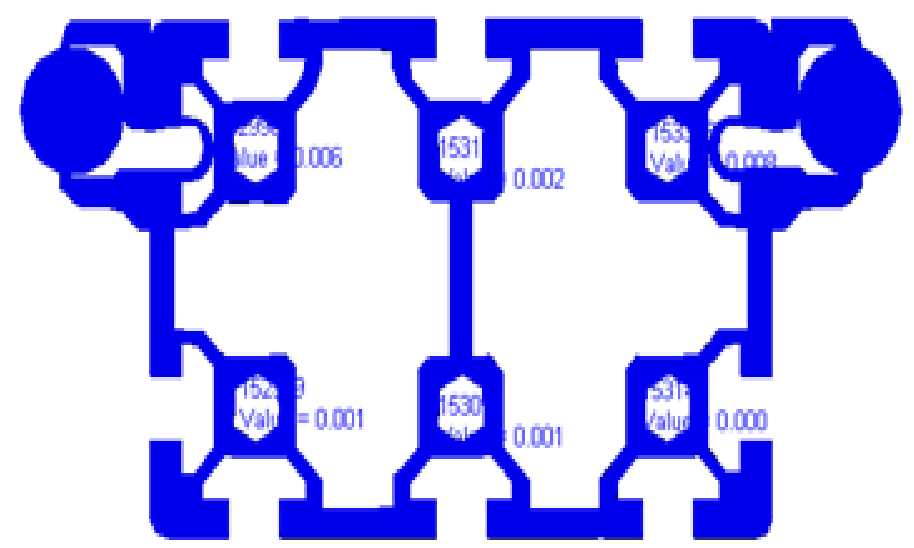

Fig 9 Maximum Stress at beam section for case-1 
Load Case: 2(995mm middle position)

4. Total maximum displacement: $0.373 \mathrm{~mm}$

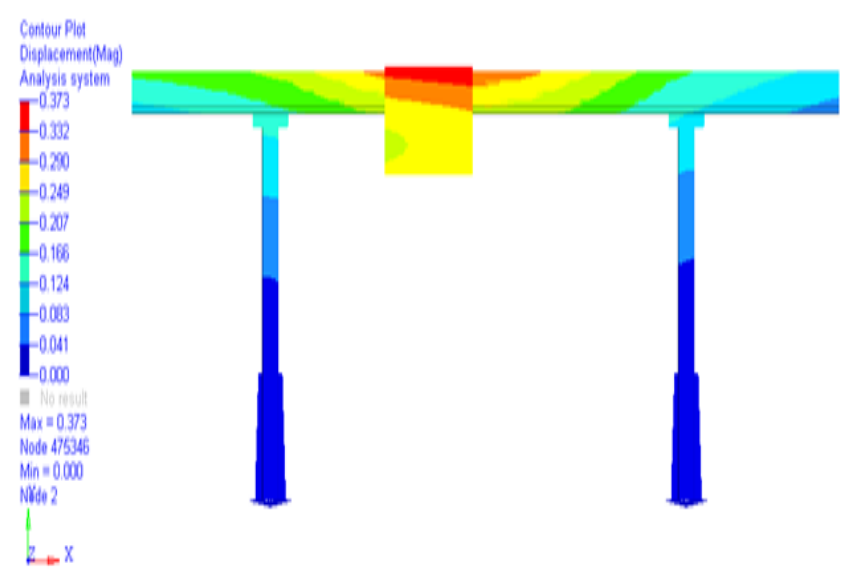

Fig 10 Maximum displacementfor case-2

5. A Total Maximum Stress: 6.418 Mpa (Safer Limit Compared To Yield Stress 240mpa)

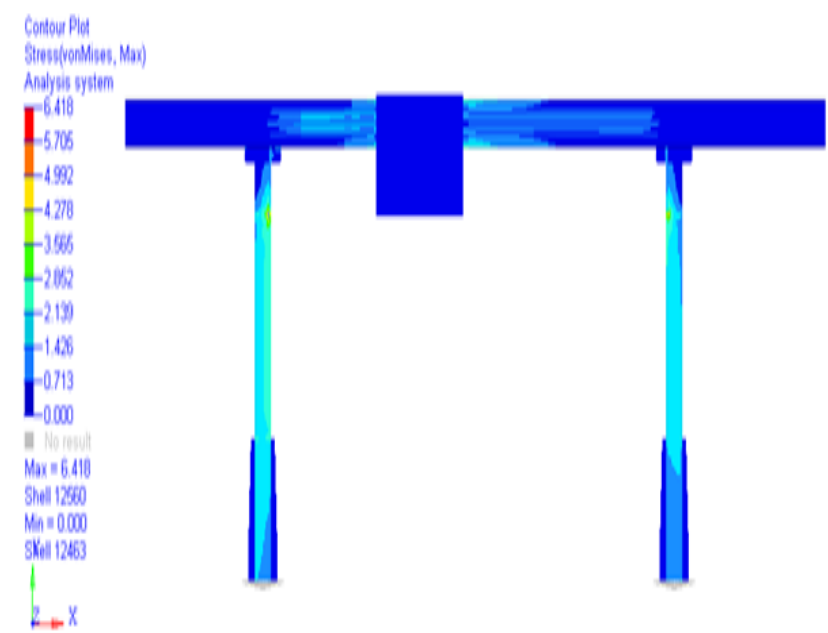

\section{Fig 11 .1.aximum Stress for case-2.}

\section{B Maximum Stress At Beam Section}

This section we got minimum stress Such as $0.011 \mathrm{Mpa}$, $0.003 \mathrm{Mpa}$ and 0.015 Mpa.

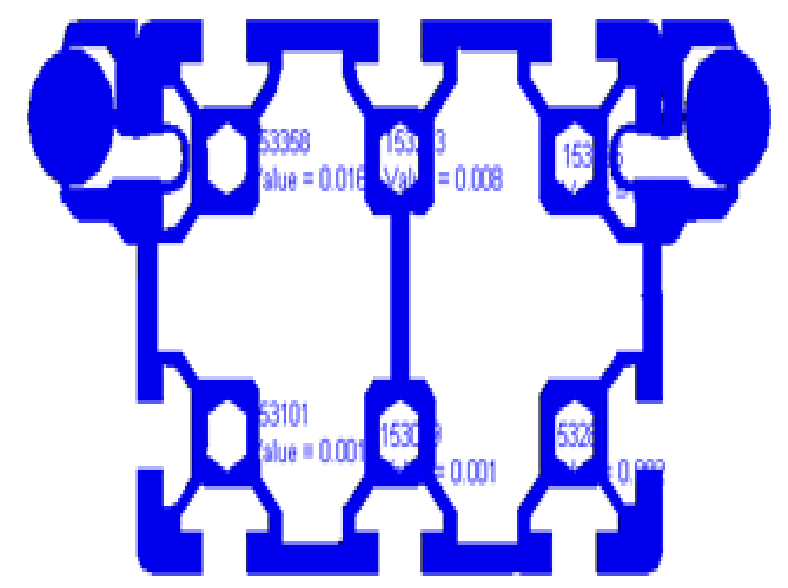

Fig 12 Maximum Stress at beam section for case-2

\section{A Maximum Shear Stress Areas : 2.424mpa}

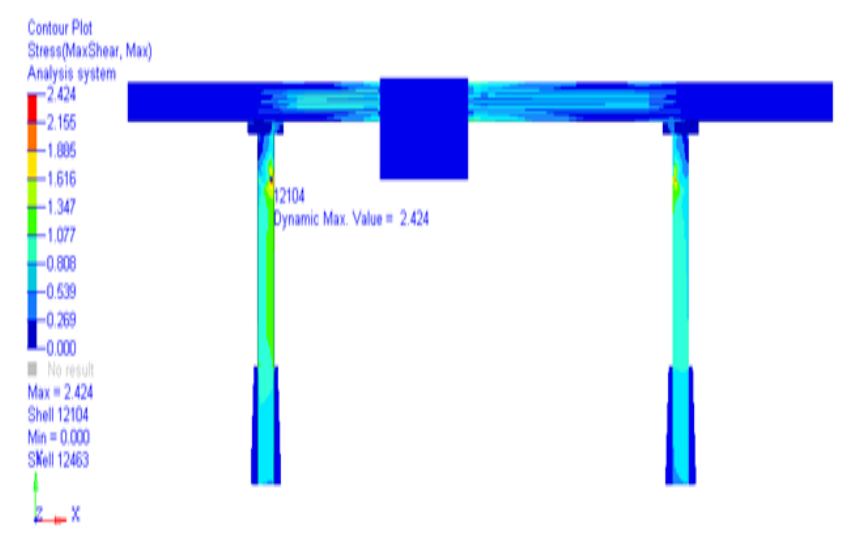

Fig 13 .Iaximum Shear Stress for case-2

\section{B) Maximum Shear Stress At Beam Section}

These sections we got minimum stress such as $0.008 \mathrm{Mpa}$, $0.005 \mathrm{Mpa}, 0.001 \mathrm{Mpa}$

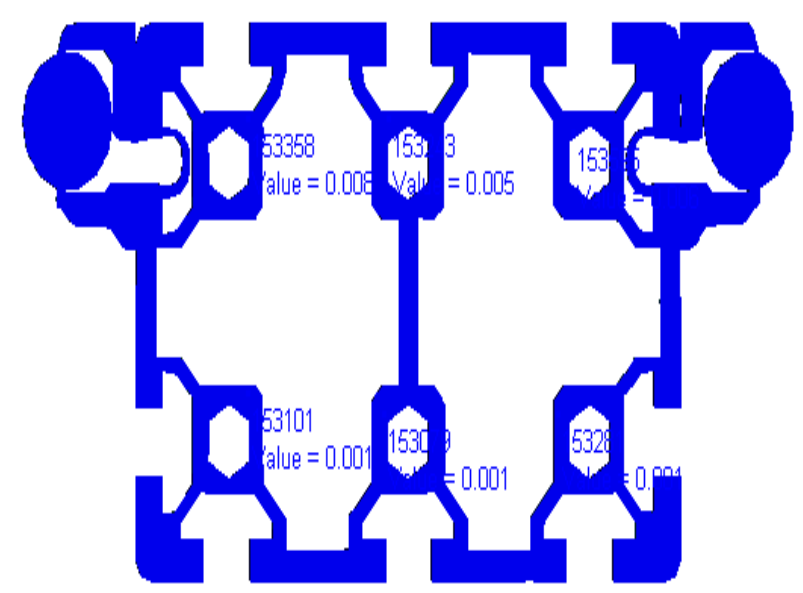

Fig. 14 Maximum Shear Stress At Beam Section For

Case-2

Load case: $3(485 \mathrm{~mm}$ middle position)

7. Total maximum displacement:0.316 mm

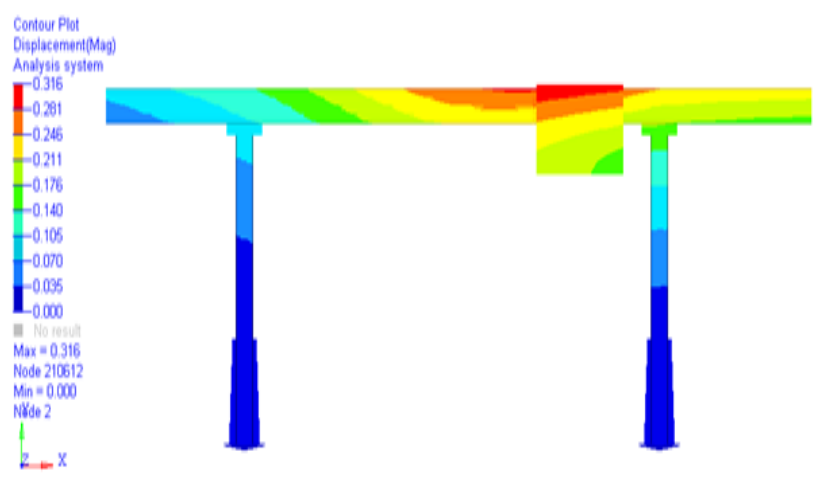

Fig. 15 Maximum displacement for case-3

Published By:

Blue Eyes Intelligence Engineering \& Sciences Publication

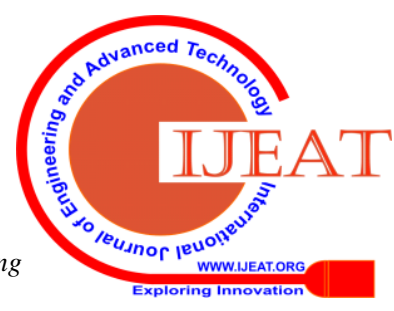


8. A. Total Maximum Stress: 5.378 Mpa (Safer Limit Compared To Yield Stress 240mpa)

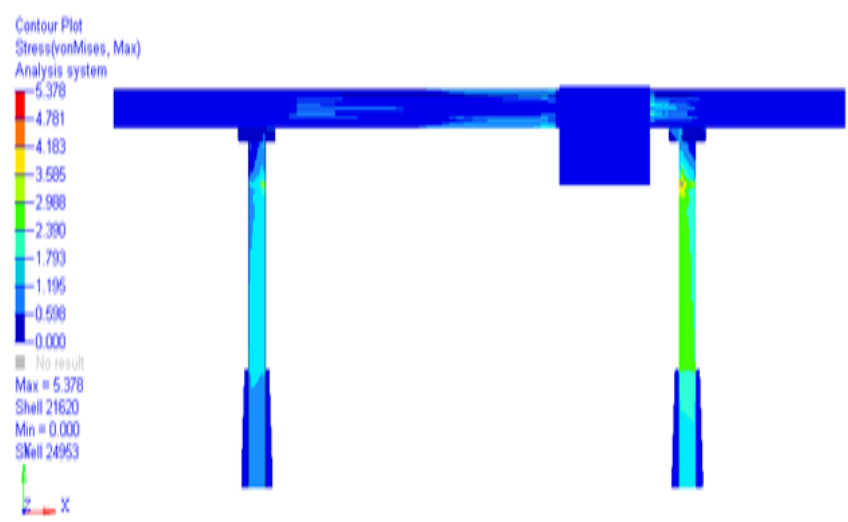

Fig 16.1Laximum Stress for case-3

\section{B. Maximum Shear Stress At Beam Section}

These sections we got minimum stress Such as $0.008 \mathrm{Mpa}$, $0.005 \mathrm{Mpa}, 0.001 \mathrm{Mpa}$

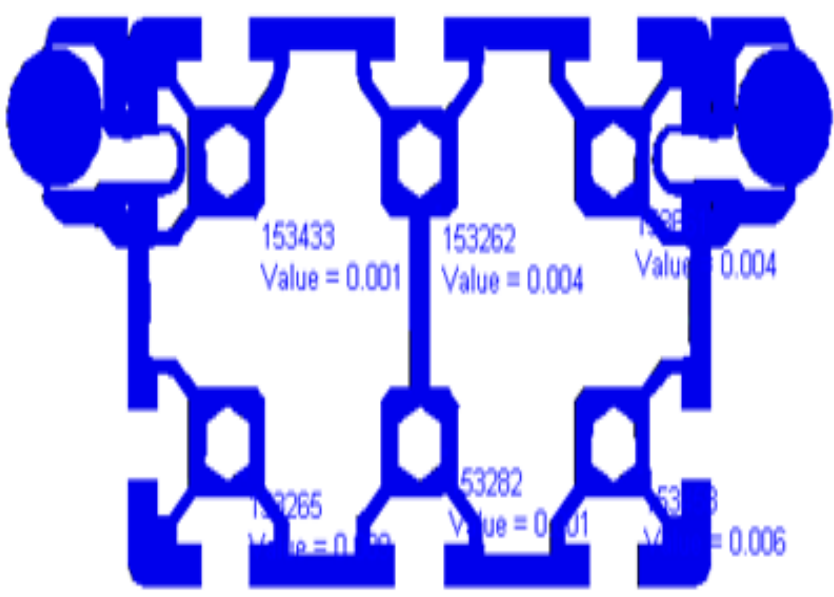

Fig 17 Maximum Stress at beam section for case-3

9. A Maximum Shear Stress Areas: 2.711mpa

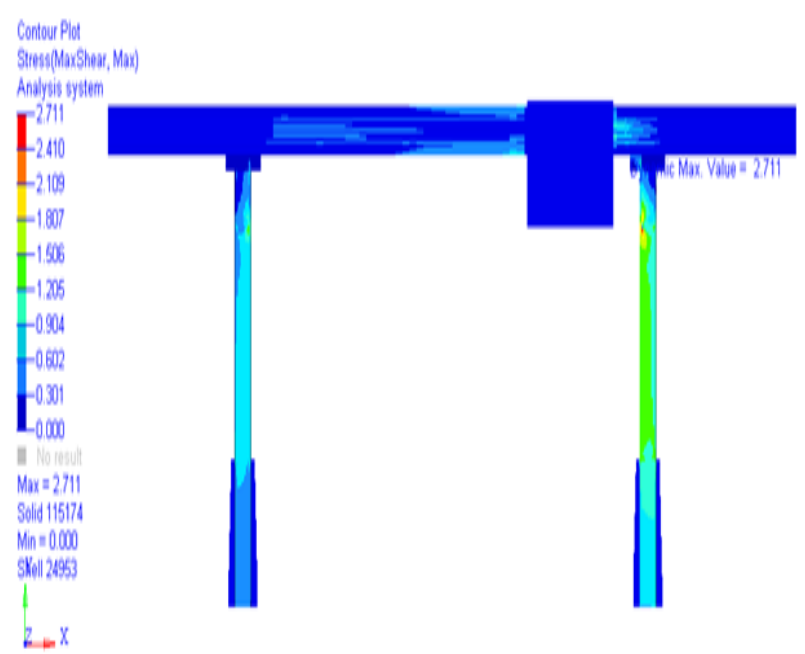

Fig 18.12asimum Shear Stres for case-3

\section{B Maximum Shear Stress At Beam Section}

These sections we got minimum stress: $0.001 \mathrm{Mpa}, 0.004$ Mpa, 0.006 Mpa

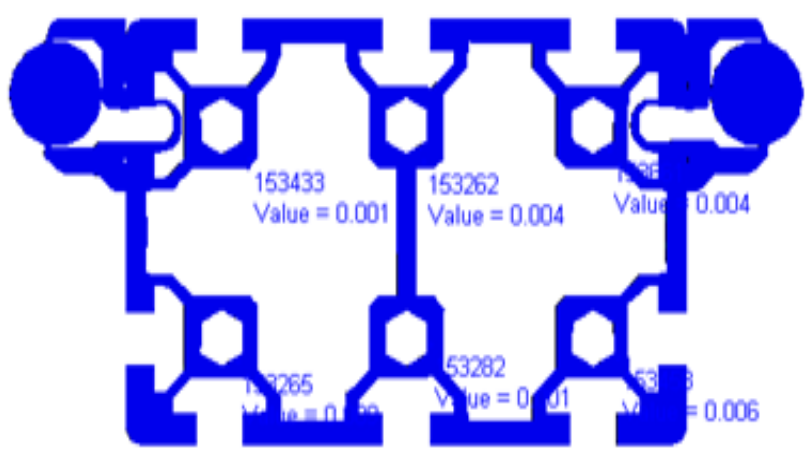

Fig 19 Maximum Shear Stress at beam section for case-2

Load Case: 4 (575 mm Right Ends)

10. Total Maximum Displacement: 0.559 Mm

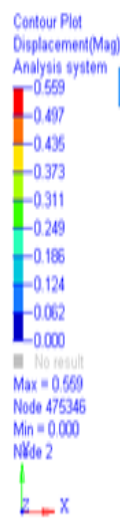

Fig 20 Maximum displacement for case-4

11.A Total Maximum Stress: 8.646 Mpa (Safer Limit Compared To Yield Stress 240mpa)

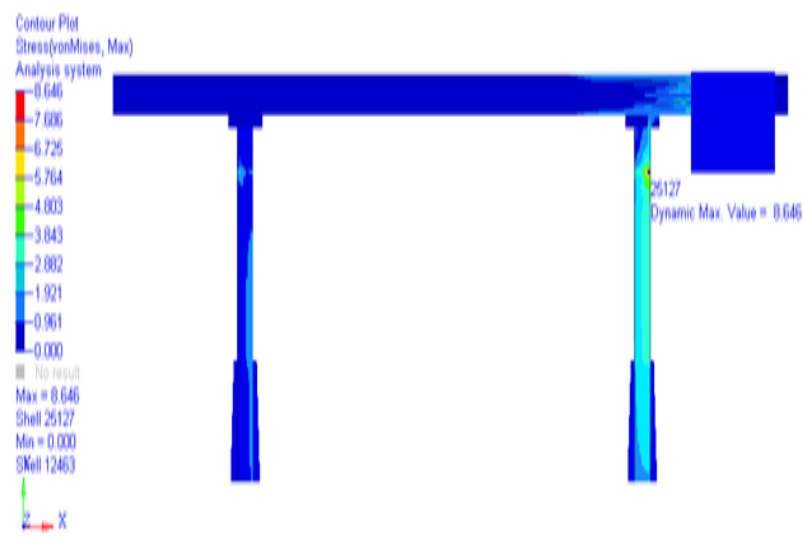

Fig 2 Maximum Stressforcase-4 


\section{B Maximum Shear Stress At Beam Section}

These sections we got minimum stress such as $0.001 \mathrm{Mpa}$, 0.003 Мpa , 0.006 Мpa.

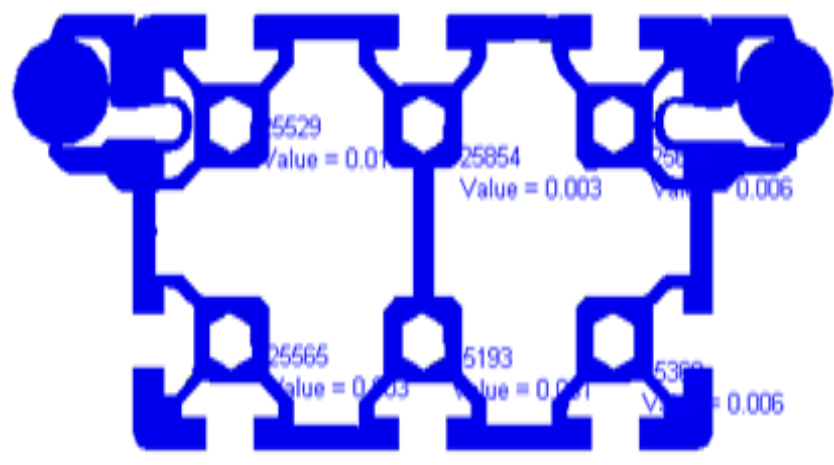

Fig 22 Maximum Stress at beam section for case-4

\section{A. Maximum Shear Stress Areas: 3.891 Mpa}



\section{Fig 23. Nlaximum Shear Stress for case-4}

\section{B Maximum Shear Stress At Beam Section}

These sections we got minimum stress such as $0.001 \mathrm{Mpa}$, $0.002 \mathrm{Mpa}, 0.004 \mathrm{Mpa}$

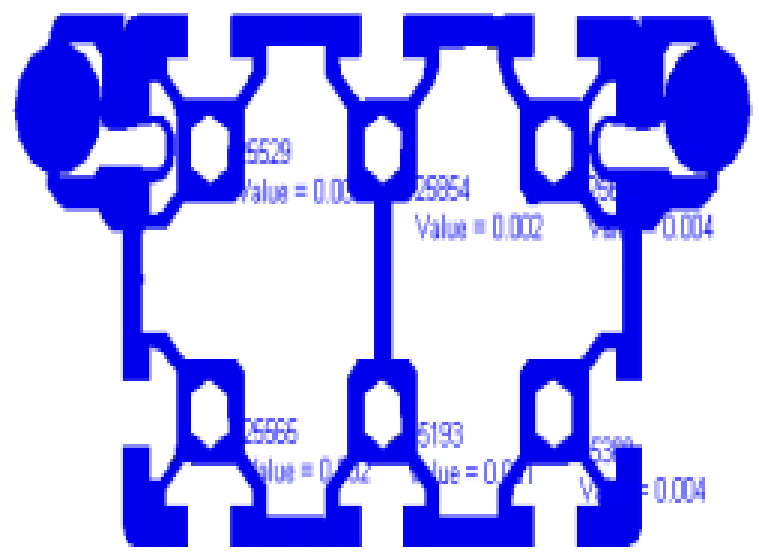

Fig 24 Maximum Shear Stress at beam section for case -4

Fig. 24 Maximum Shear Stress at beam section for case-4

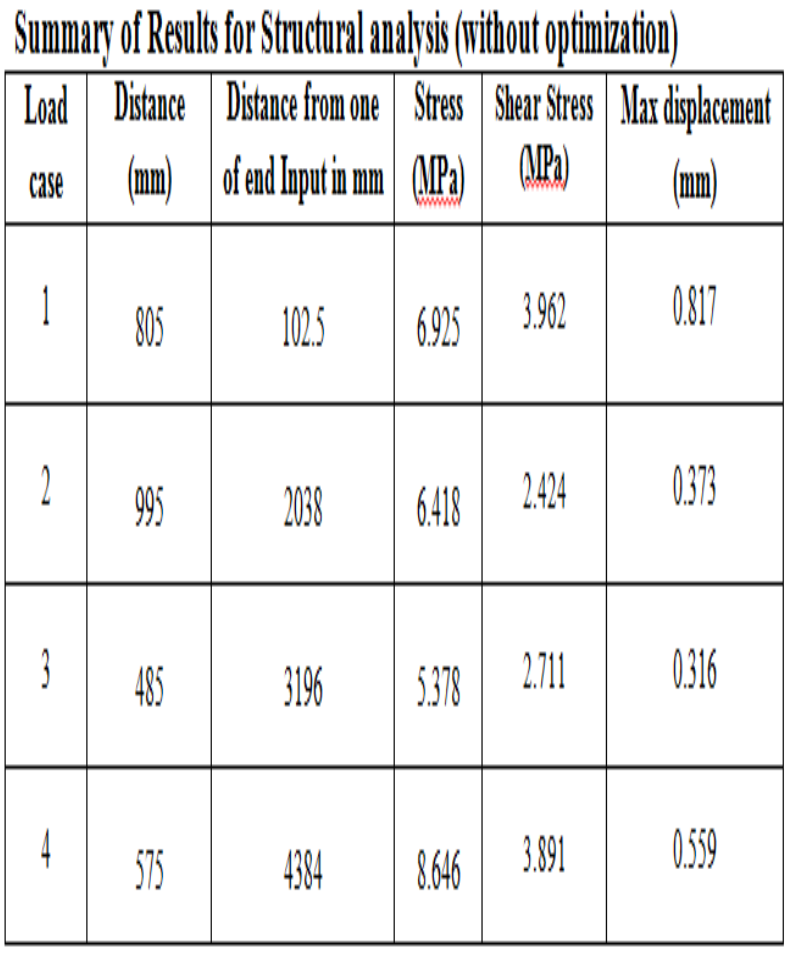

Optimization Of Gantry Structure Optimization means add or remove of material for the cost effective as well as how engineer needs that by that stresses may vary definitely with that strength and stiffness too. So it depends on system how should operate the thing reduce or increase.

1. Constrained optimization problem: which related to one or more constraints?

2. Unconstrained optimization problems: no constraint in this.

Types of structural optimization:

- Size optimization

- Shape optimization

- Topology optimization

Shape optimization: in this main aim to find out optimal shape to minimize a certain thing of that cost function. Size optimization: it considers that optimal thickness member of truss $\mathrm{c} / \mathrm{s}$, changing the thickness of member whole structure has less stress. Topology optimization: it optimizes the material layout within that design and under condition of boundary. Engineers used this for best dynamic structure to have high natural frequency. Will get best conceptual design that satisfies objective design. Topology optimization used at manufacturability of conceptual design. topology replaces time consuming and costly design hence reduces the cost and improve design performance [8]. It implemented through use of FEM for analysis, its technique based on genetic algorithm, topological derivatives 
Load Case: 1(805mm Left End)

A.Optimized max displacement: $1.179 \mathrm{~mm}$



Fig 25 Optimized Maximum displacement for case-1

B. Optimized maximum stress: 23.49 mpa

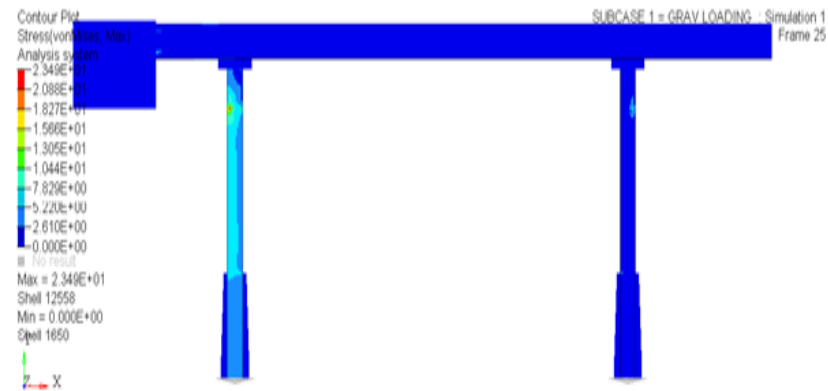

Fig 26 Optimized Maximum Stress for case-1

C.Optimized maximum shear stress: $8.53 \mathrm{mpa}$

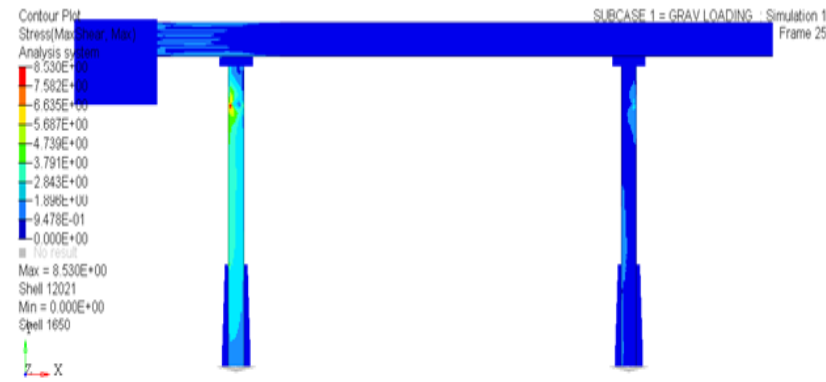

Fig 27 Optimized Maximum Shear Stress for case-1

Load case: 2(995mm middle position)

A.optimized maximum displacement: $5.565 \mathrm{~mm}$

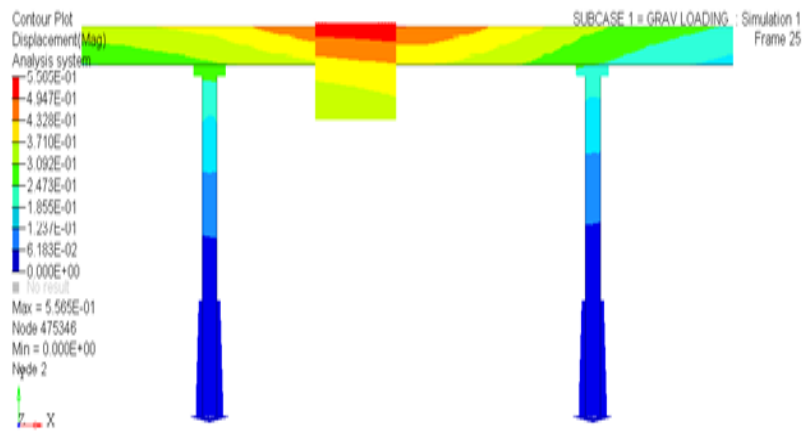

Fig 28 optimized Maximum displacement for case-2

Retrieval Number: B4407129219/2019@BEIESP

DOI: 10.35940/ijeat.B4407.129219

Journal Website: www.ijeat.org
B. Optimized maximum stress: 15.04mpa

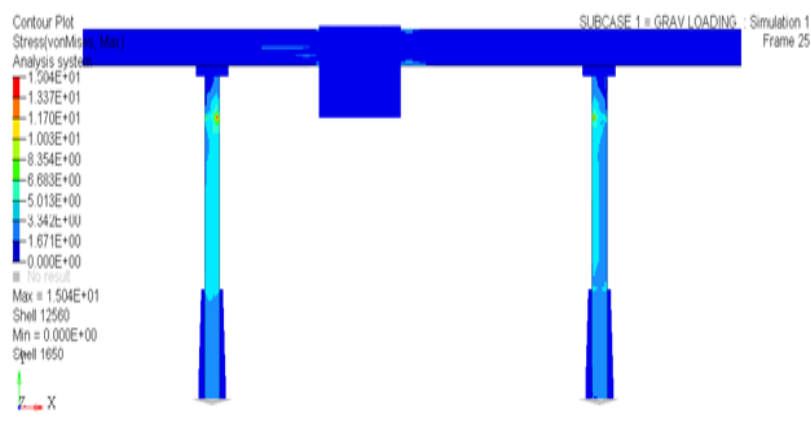

Fig 29 Optimized Maximum Stress for case-2

C. Maximum shear stress: $5.502 \mathrm{mpa}$

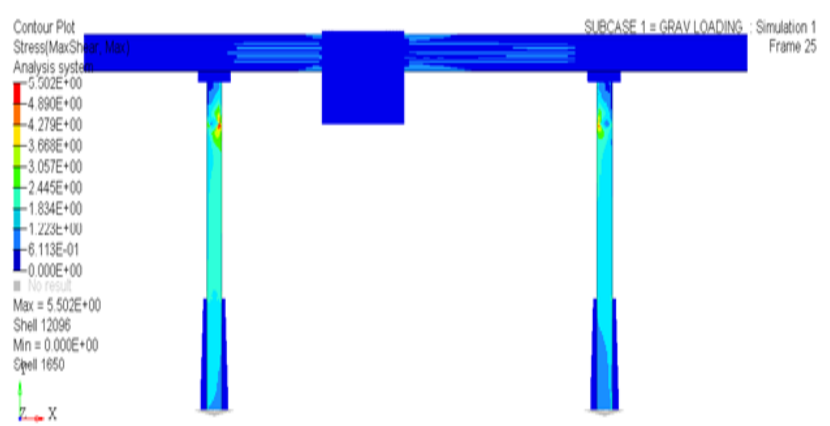

Fig 30 Optimized Maximum Shear Stress for case-2

Load case: $3(485 \mathrm{~mm}$ middle position)

A.Total maximum displacement: $0.517 \mathrm{~mm}$

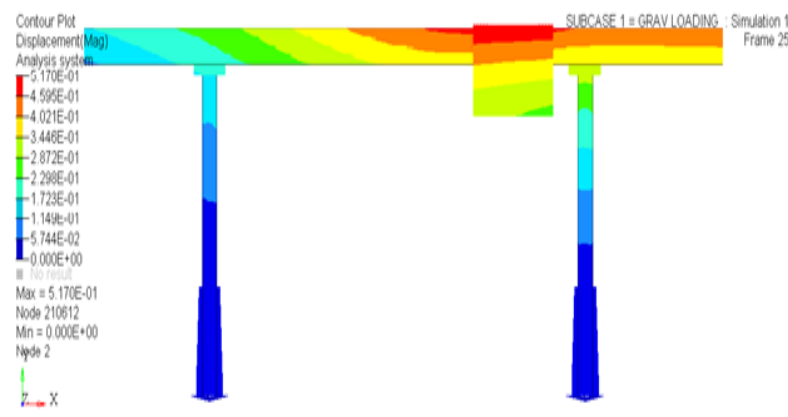

Fig 31 Optimized Maximum displacement for case-3

B. Optimized maximum stress: $17.10 \mathrm{mpa}$

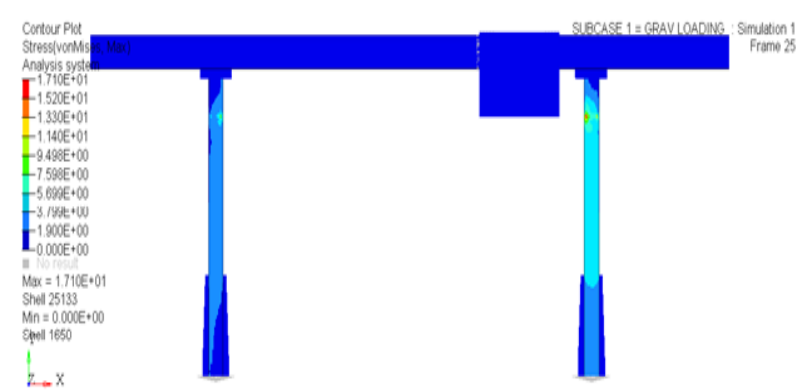

Fig 32 0ptimized Maximum Stress for case-3

Blue Eyes Intelligence Engineering \& Sciences Publication 


\section{C.Optimized maximum shear stress: 6.129mpa}

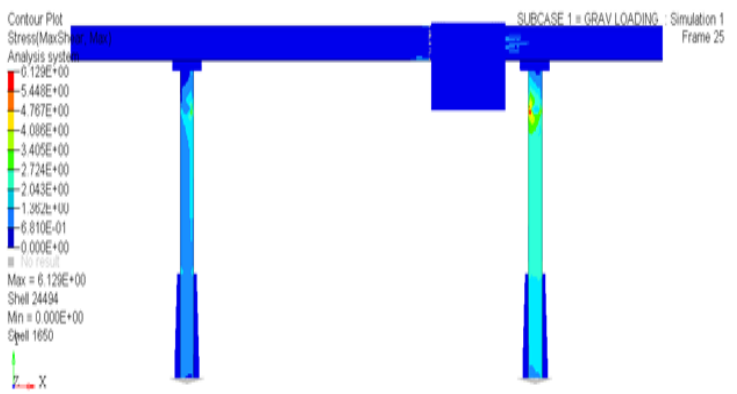

Fig 33 Optimized Maximum Shear Stress for case-3

Load case: $4(575 \mathrm{~mm}$ right end)

A. total maximum displacement: $0.8950 \mathrm{~mm}$

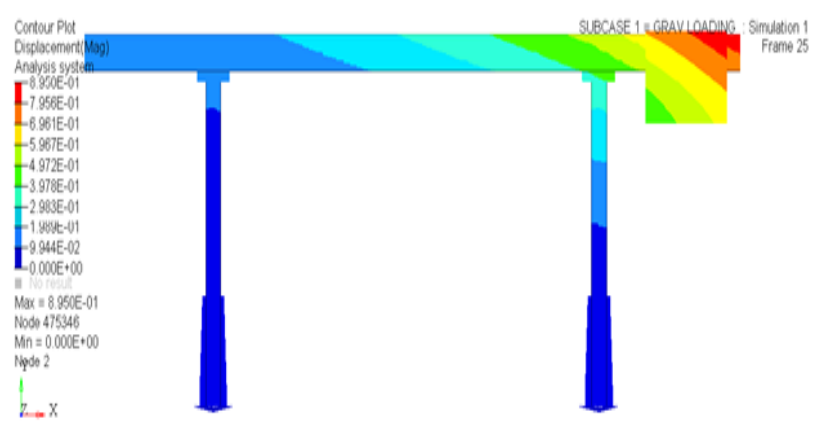

Fig 34 Optimized Maximum displacement for case-4

B. Optimized maximum stress: $21.44 \mathrm{mpa}$

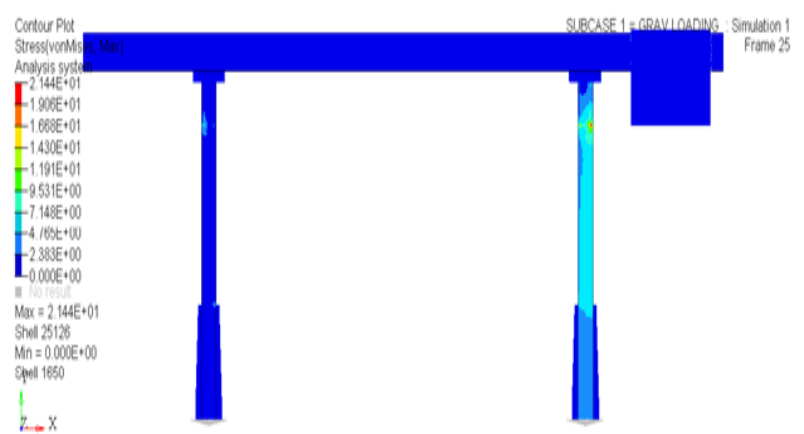

Fig 35 Optimized Maximum Stress for case-4

\section{Optimized Shear Stress: 7.779mpa}

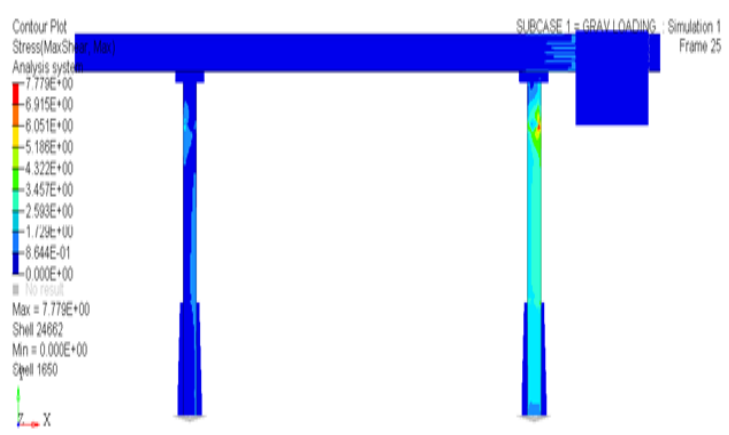

Fig 36 Optimized Maximum Shear Stress for case-4 summary of results for structural analysis(with optimization)

- The stresses and displacements varied from the one case to other

- After the optimization stresses are became more and

displacement also.
\begin{tabular}{|c|c|c|c|c|c|}
\hline $\begin{array}{c}\text { Load } \\
\text { case }\end{array}$ & $\begin{array}{c}\text { Distance } \\
(\mathrm{mm})\end{array}$ & $\begin{array}{c}\text { Distance from one } \\
\text { of end Input in mm }\end{array}$ & $\begin{array}{c}\text { Stress } \\
(\mathrm{MPa})\end{array}$ & $\begin{array}{c}\text { Shear Stress } \\
(\mathrm{NPa})\end{array}$ & $\begin{array}{c}\text { Max displacement } \\
(\mathrm{mm})\end{array}$ \\
\hline 1 & 805 & 102.5 & 23.49 & 8.53 & 1.179 \\
\hline 2 & 995 & 2038 & 15.04 & 5.50 & 0.556 \\
\hline 3 & 485 & 3196 & 17.10 & 6.13 & 0.517 \\
\hline 4 & 575 & 4384 & 21.44 & 7.79 & 0.890 \\
\hline
\end{tabular}

\section{MODAL ANALYSIS}

Natural frequency defined to mode, modal damping and mode shape. If boundary condition of structure changed than modes also change Consider that mass added to a pump vertical it vibrates because mode changed. Natural frequency of a mode the overall operating deflection shape of the machine will dominate by mode shape of resonance. Operating deflection shape means on structure any forced motion that of two or more points.

Normal Mode Analysis: Free Free Analysis is done to Check Model for Errors

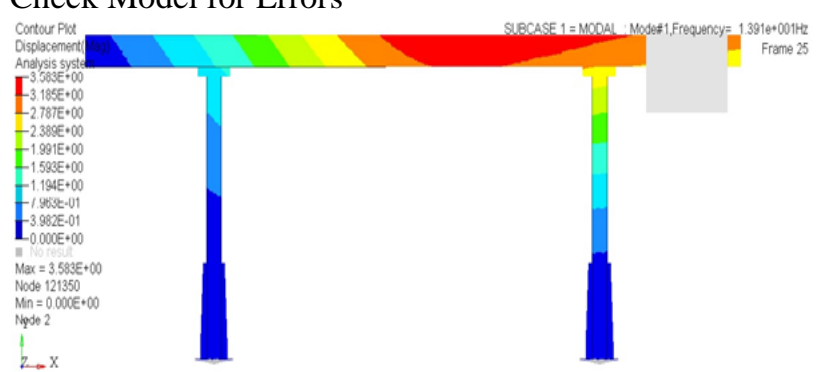

Fig 37 Model \# $\mathrm{l}$ at Frequency $13.91 \mathrm{HZ}$ at a Maximum displacement $35.83 \mathrm{~mm}$

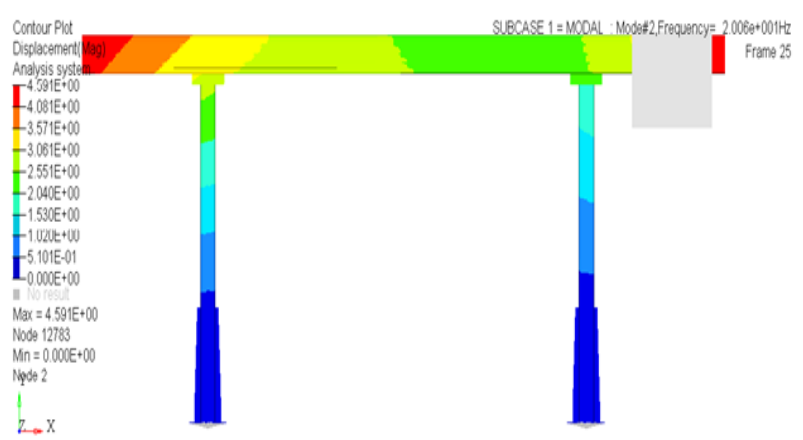

Fig 38 Model \# 2 at Frequency $20.06 \mathrm{HZ}$ at a Maximum displacement $45.91 \mathrm{~mm}$

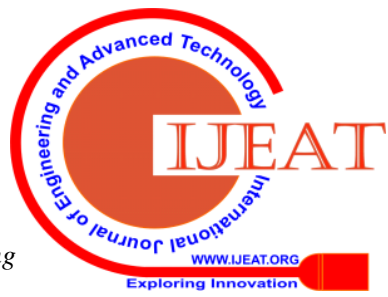




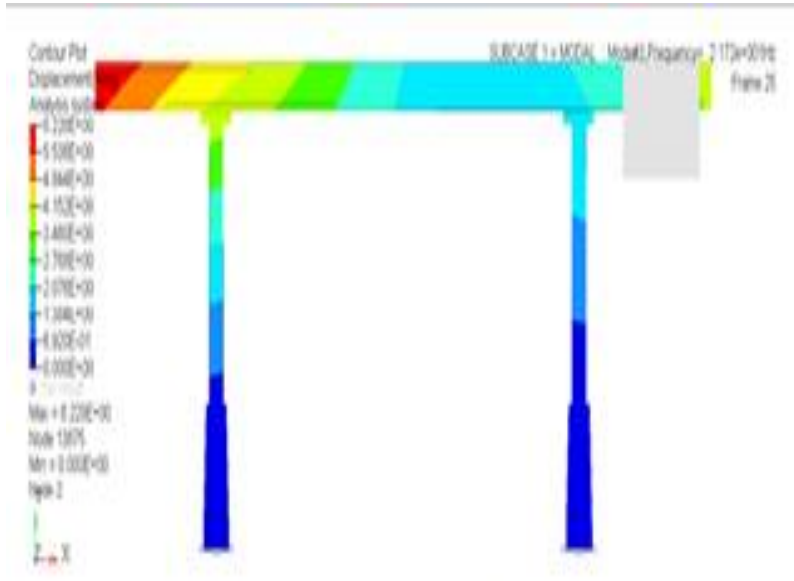

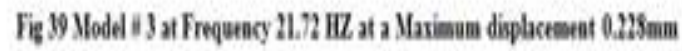

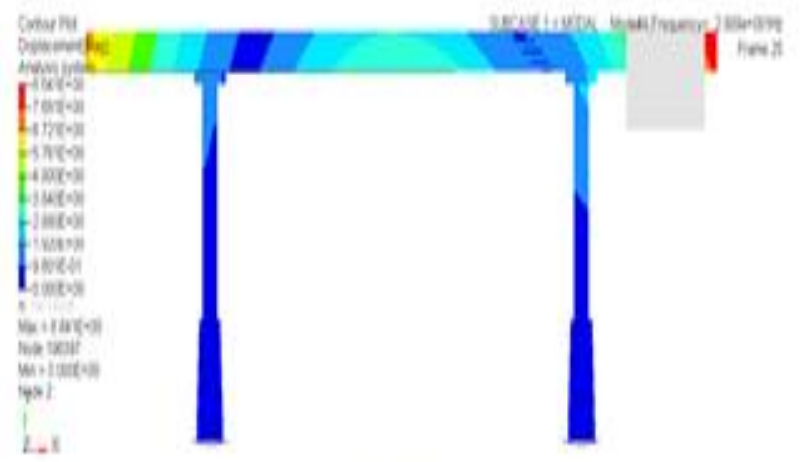

Fig 40 Nodel it 4 at Frequency 28.09 IIZ at a Narimume displaceanat 8.041 mem

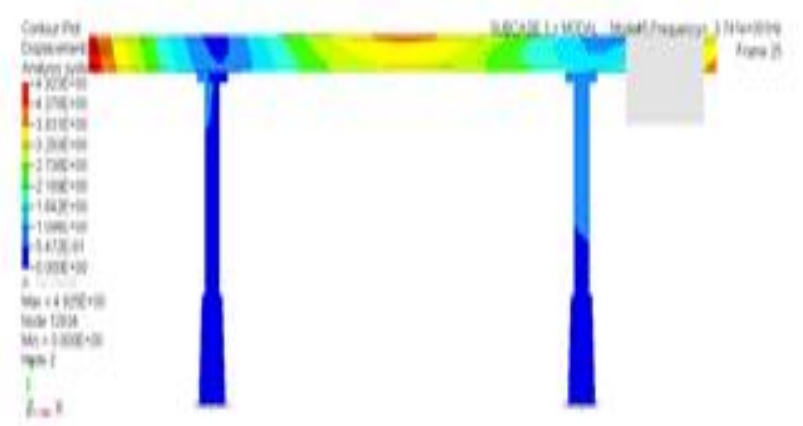

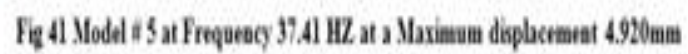

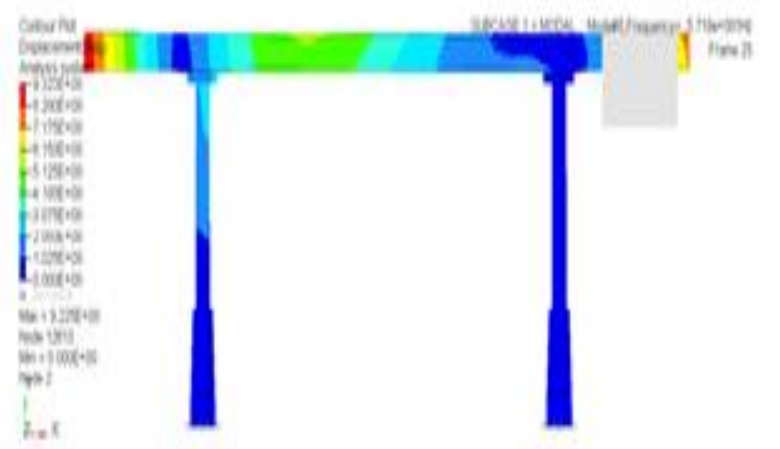

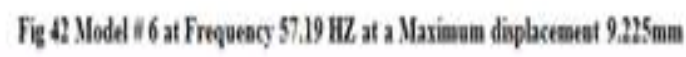

Retrieval Number: B4407129219/2019@BEIESP

DOI: 10.35940/ijeat.B4407.129219

Journal Website: www.ijeat.org

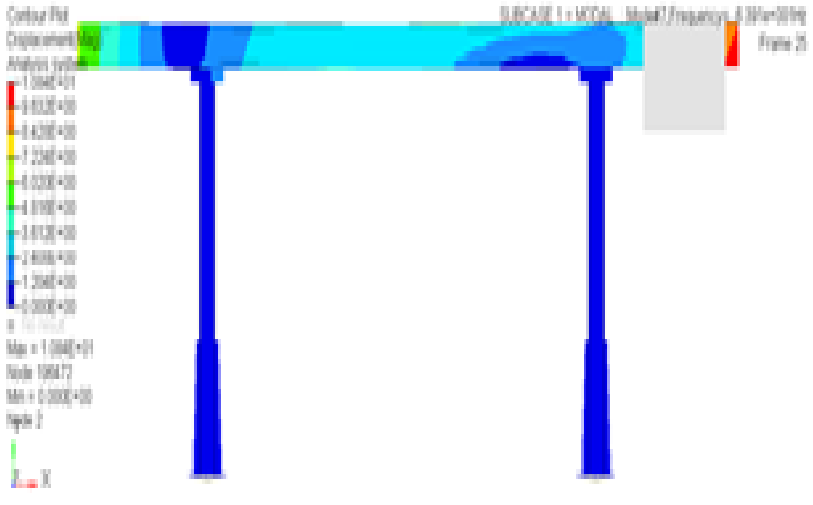

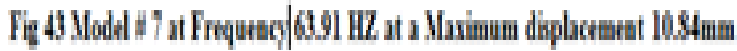

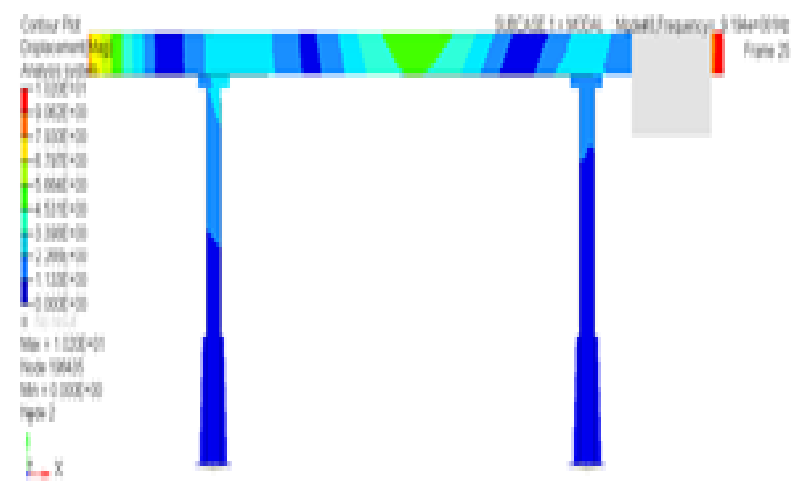

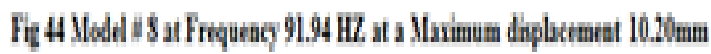

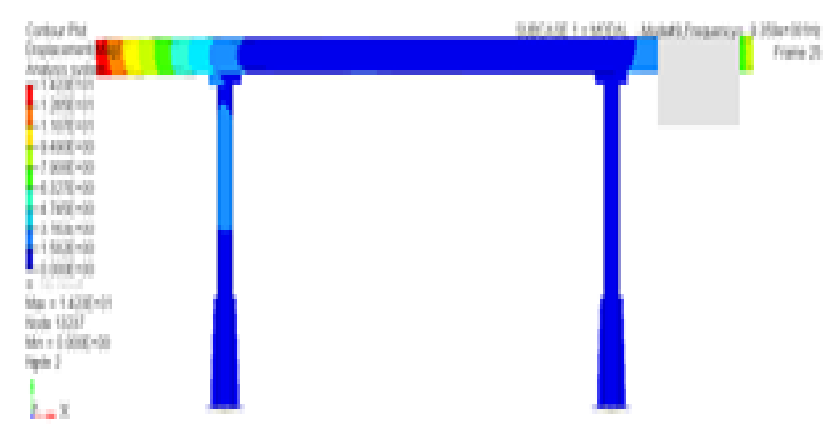

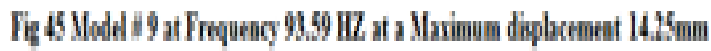

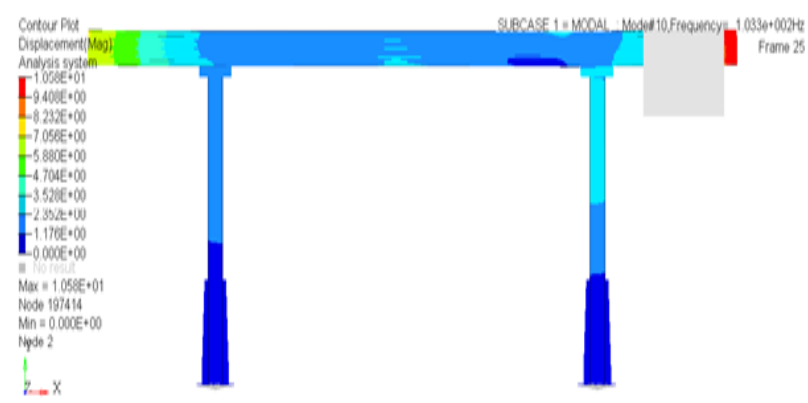

Fig 46 . Model \# 10 at Frequency $103.3 \mathrm{HZ}$ at a .Maximum displacement $10.08 \mathrm{~mm}$

Published By:

Blue Eyes Intelligence Engineering \& Sciences Publication 


\section{CONCLUSIONS}

In this paper Gantry structure completely analysed from FEM software, the beam which is under the load subjected to the structural analysis the stress we got is $8.646 \mathrm{Mpa}$ and shear is 3.891Mpa with that displacement $0.559 \mathrm{~mm}$ this is of before optimization result, and the result this is of maximum out of four loading condition the right end of the gantry which having highest stress, so that considering we optimized the gantry structure the stress got in this is maximum stress is 23.49 Mpa and shear is 7.79Mpa ,displacement $0.890 \mathrm{~mm}$.

The results compared stress is increased because of reducing the thickness of the column of gantry structure, so we see here is after optimize the stress is doubled compared to actual design with displacement. To the model modal analysis is carried out which having the frequency of mode shape 09 is $14.25 \mathrm{~mm}$ of maximum displacement. The strength and stiffness of material which is maintained high itself by varying the thickness.

\section{REFERENCES}

1. Y. Li, Lijiang, cilium and, g. line," static rigidity analysis and structure optimization of five axis gantry type machining center "modular machine tool automatic manufacturing technique,vol.53, no.6, pp. 9-16,2011

2. "The design and optimization of large scales heavy gantry NC machining center based on FEM. Bys.bxu, k.k.sun,c.njng,andg.cren" vols697-698(2012) pp 656-660.

3. "Structural optimization of the cross beam of a gantry machine tool based on grey relational analysis by shihaoolie. Yue li, yulanlio.Zhizhongaguo 21 December 2013

4. Wang, j.zia, f yang, and s.jhang, "The topological optimation design and analysis for gantry machine tool cross beam component" manufacturing technology machine vol.59, no.11, pp. 64-68, 2009

5. "The gantry-tau parallel kinematic machine and Electrodynamics design optimization mechanical(2011)46:113-129

6. "Static analysis for the cross beam of large gantry cnc machine under six working conditions "by Xiaolieding, weaningyang, and jiamchnwang." vols 605-607(2013) pp 1523-1526.

7. "FEA and optimization of long span gantry NC machining center structure"" by shubhoxua, yang xi.cainianjig. KekeSn. Vol346 (2012) pp 379-384.

8. "Gantry's structural analysis on beam". By woo li-wing, li yao fi, yang shi longa, wanzeekai. Vol 543-547(2014) pp 50-54.

9. "Fast design and analysis of large gantry machine center based on unit structure "by lijjeacoo, weifangchn, yuzhichina, andwenhua yea."Vols 490-491(2014) pp682-686.

10. "Optimization design for large gantry machining center crossbeam. By Qing hung, Weifangchin, whenua ye, peihuanglandshihao li. "applied mechanics and material voles 130-134(2012)pp2284-2287

11. "Modal analysis of the gantry milling and boring machine tool beam based on FEM", guoquango, "applied mechanics and materials vol 151(2012) pp424-428

12. “Analysis and design of gantry support frame.” By lingo he, gaokizing, hengyuawu, yali li, xhigangwanga.vols 271-272(2013)pp762-766

13. B. li, z. Fang, and q. Liang, "deformation analysis and optimization for the beam rails of the fix beam gantry machine center" electrical engineering technology, vol. 40, no .11, pp. 104-145, 2010.

14. Wang, j.zia, f yang, and s.jhang, "The topological optimation design and analysis for gantry machine tool cross beam component" manufacturing technology machine vol.59, no.11, pp. 64-68, 2009

15. Li qilang, go dugong, cueYao, jigwenzhng, wanLiang and hangtao, "mechanical analysis of crossbeam in a gantry machine tool and its deformation compensation. College of mechanical engineering .Soochow university, Jiangsu215006, p.r.china.Vol. 9,pp .213-218,2015

16. B.J.Daias, F.V.De, "designer and optimization of a lightweight aluminum gantry system", Norwegian University of science and technology, Oct 2013.

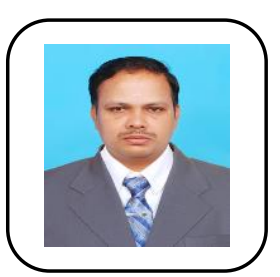

\section{AUTHORS PROFILE}

Dr. V. Balaji, completed his $\mathrm{PhD}$ from Bharath Institute of Higher Education and Research (BIHER) under the Faculty of Mechanical Engineering, Chennai, India. He is working as an Professor and Principal at Sri Sai Institute of Technology and Science, Rayachoty, Andhra Pradesh. His research interest includes Machining, Design and Analysis, Manufacturing etc., He has published 10 papers in international journals. He has around 14 years of experience in both teaching and industry. http://orcid.org/0000-0003-4483-777X

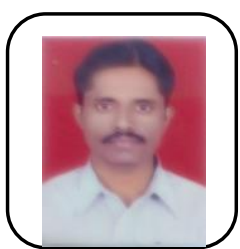

Dr. Selvam, received a doctoral award from Bharath Institute of Higher Education and Research (BIHER) under the Faculty of Mechanical Engineering, Chennai in the field of Nano Composite materials in 2019. Currently $\mathrm{He}$ is working as a Professor in Saveetha Engineering College, Chennai, Tamiulnadu. $\mathrm{He}$ has Published 6 Papers in International Journals. He worked in both industries and Educational Institutions 